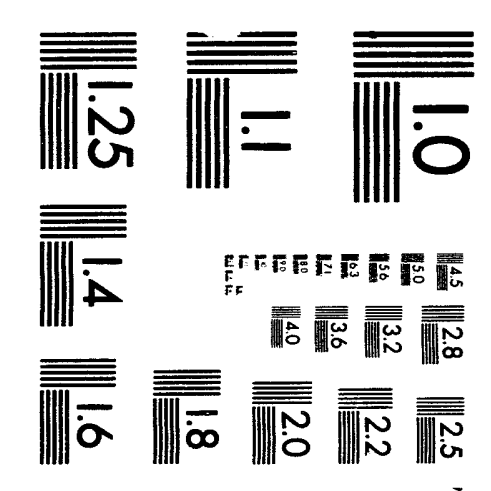



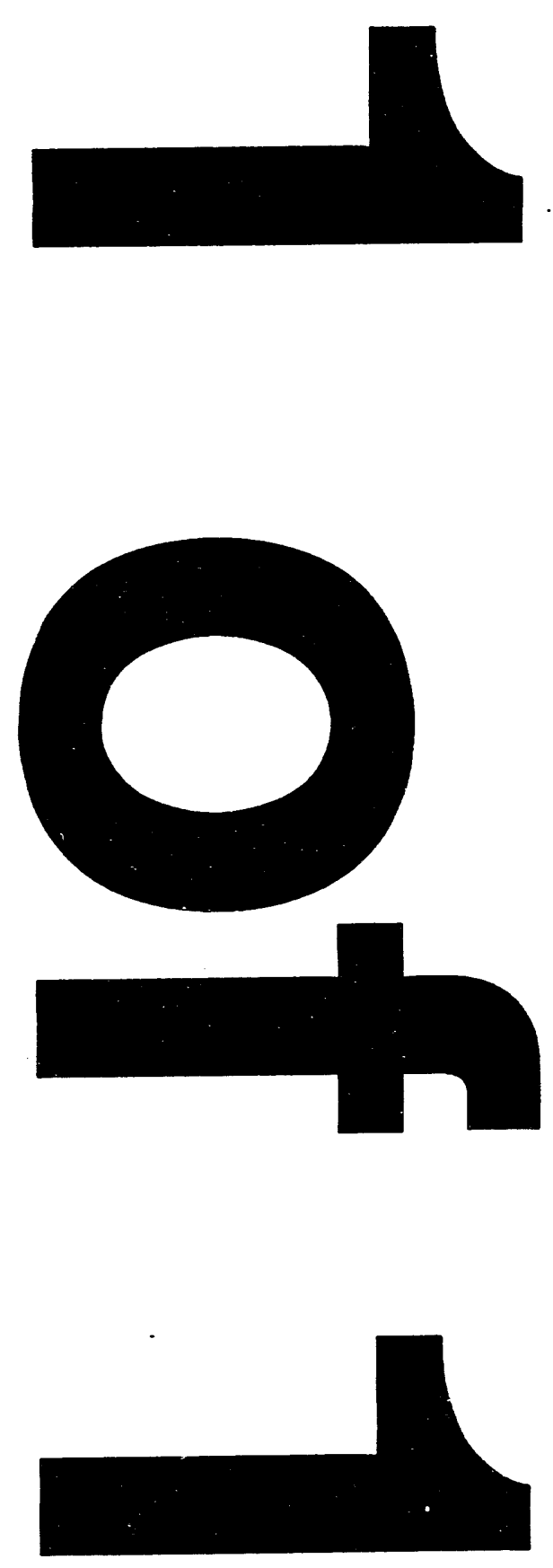


\title{
EFFECT OF PRECIPITATE STRUCTURE ON HOT DEFORMATION OF AT-Mg-Mn ALLOYS
}

\author{
J. S. Vetrano \\ C. A. Lavender \\ M. T. Smith \\ S. M. Bruemmer
}

October 1993

Presented at the

Materials Week ' 93 Conference

October 17-21, 1993

Pittsburgh, PA

Work supported by

the U.S. Department of Energy

under Contract DE-ACO6-76RLO 1830

MASTER

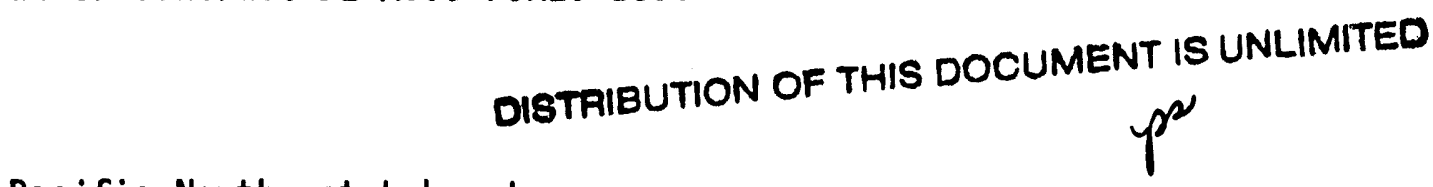

Pacific Northwest Laboratory

Richland, Washington 99352

\section{DISCLAIMER}

This report was prepared as an account of work sponsored by an agency of the United States Government. Neither the United States Government nor any agency thereof, nor any of their employees, makes any warranty, express or implied, or assumes any legal liability or responsibility for the accuracy, completeness, or usefulness of any information, apparatus, product, or process disclosed, or represents that its use would not infringe privately owned rights. Reference herein to any specific commercial product, process, or service by trade name, trademark, manufacturer, or otherwise does not necessarily constitute or imply its endorsement, recommendation, or favoring by the United States Government or any agency thereof. The views and opinions of authors expressed herein do not necessarily state or reflect those of the United States Government or any agency thereof. 


\title{
EFFECT OF PRECIPITATE STRUCTURE ON HOT DEFORMATION OF AI-Mg-Mn ALLOYS
}

\author{
J.S. Vetrano, C.A. Lavender, M.T. Smith and S. M. Bruemmer \\ Pacific Northwest Laboratory \\ Richland, WA 99352
}

\begin{abstract}
The size and nature of precipitates have strong effects on microstructural evolution from the cold-worked state through the course of deformation at high temperatures. Through selected heat treatments and minor alloying alterations the precipitate structure of AA5083 has been manipulated. Minor additions of $\mathrm{Zr}$ have been used to create fine $(50$ to $100 \mathrm{~nm})$ precipitates. The number and size distribution of "medium-sized" $(<1 \mu \mathrm{m})$ Mn-rich precipitates were modified by increasing the $\mathrm{Mn}$ concentration in conjunction with several heat treatment paths. Effects of these precipitates on the dislocation structure, recrystallization behavior and grain growth during high-temperature deformation have been elucidated.
\end{abstract}




\section{Introduction}

AA5083 (Al-5Mg-0.8Mn) is a high-use, inexpensive, weldable aluminum alloy. The combination of low cost and good mechanical properties of AA5083 has led to an interest in using this alloy for superplastic forming (1-5). Lloyd (1) noted that though a standard, commercial 5083 alloy showed a high strain-rate sensitivity (one of the features of a superplastic material) without any special thermomechanical processing (TMP), the elongation was limited to about $130 \%$ by extensive cavitation. Subsequent studies have demonstrated improved (up to $700 \%$ ) elongations by increasing the purity $(2,3)$, adding small amounts of $\mathrm{Cu}(4)$ and improved TMP to decrease the grain size (5).

It is the precipitates in these 5083-based alloys that allow the creation of a fine grain size by simple TMP, and give this material good superplastic potential (4-8). The typical precipitate structure of 5083 generally consists of two types: large dispersoids (Al-based intermetallics containing $\mathrm{Mn}, \mathrm{Cr}, \mathrm{Fe}$ and $\mathrm{Si}$ in various ratios) that are formed during casting, and submicron $\mathrm{Al}_{6}(\mathrm{Mn}, \mathrm{Cr})$ particles that precipitate during cooling. In addition, the alloy containing $\mathrm{Cu}$ mentioned above contained fine $\mathrm{Al}-\mathrm{Mn}-\mathrm{Cu}$ and $\mathrm{Al}-\mathrm{Mg}-\mathrm{Cu}$ precipitates (4). Hot rolling treatments break down the as-cast, large dispersoids into particles in the 2- to $10-\mu \mathrm{m}$ size range. This treatment can also affect the size distribution of the smaller $\mathrm{Al}_{6}(\mathrm{Mn}, \mathrm{Cr})$ precipitates.

Several articles have been published concerning the role of $\mathrm{Mn}$-rich particles on the recrystallization and hot-working characteristics of Al-Mg-Mn alloys (6-8). Sheppard and Tutcher (6) investigated the microstructural development during hot extrusion and found that the alloy with $\mathrm{Mn}$ dynamically recrystallized, as compared to an $\mathrm{Al}-\mathrm{Mg}$ binary that showed only dynamic recovery. They attributed this change partially to increased nucleation at the Mn-rich precipitates. McQueen, Evangelista and co-workers $(7,8)$ studied the high-temperature behavior of 5083 in torsion and their results largely substantiate those of Sheppard and Tutcher (6). Additionally, their analysis of the precipitate size distribution and spacing led them to attribute the dynamic recrystallization to a pinning of the substructure by fine $(0.2$ $\mu \mathrm{m})$ particles.

Zirconium is used in many aluminum alloys as a grain refiner. It precipitates as a fine dispersion of $\mathrm{Al}_{3} \mathrm{Zr}$, sometimes in a metastable, coherent form, or incoherently in its equilibrium tetragonal structure. However, Watts et al. (9) studied the effect of $0.5 \% \mathrm{Zr}$ additions in pure $\mathrm{Al}$ and an $\mathrm{Al}-6 \mathrm{Cu}$ alloy and found that $\mathrm{Zr}$ by itself was not effective in 
restricting grain growth. This result was confirmed by Gardner and Grimes (10) on $\mathrm{Al}-\mathrm{Zr}$ and $\mathrm{Al}-\mathrm{Zn}-\mathrm{Zr}$ alloys. Nes (11) attributed substructure stabilization and sub-grain growth restriction to the fine $\mathrm{Al}_{3} \mathrm{Zr}$ particles in an $\mathrm{Al}-\mathrm{Cu}-\mathrm{Zr}$ alloy, but asserted that the high-angle grain boundaries are restricted more by the larger $\Theta$-particles ( $\mathrm{Cu}$ based precipitates).

Hot-deformation mechanisms such as superplasticity are dependent on grain size and shape. Thus, recrystallization and grain growth behavior play a critical role in hot deformation. This paper will evaluate the influence of $\mathrm{Mn}$ and $\mathrm{Zr}$ additions on recrystallization and subsequent hot deformation in a series of AA5083-based alloys. Precipitate structures in these tailored alloys will be characterized and used to explain individual alloy response.

\section{Experimental Procedures}

The materials used in this study were based on AA5083 with additions of $\mathrm{Zr}$ and $\mathrm{Mn}$ (Table I). These were purchased from Kaiser Aluminum as $25.4 \mathrm{~mm}$-thick plates after direct chill casting and high-temperature break-down rolling. Break-down rolling is used to destroy the as-cast microstructure and was carried out at two temperatures. In this paper, the samples rolled at higher (standard) temperature are designated as " $A$ " while those rolled at the lower temperature are " $B$ ".

The starting condition in all of our tests was a 5:1 cold-roll reruction to a final thickness of $1.9 \mathrm{~mm}$. Standard "dogbone" tensile : umples were cut with a gage length of $12.7 \mathrm{~mm}$ and width of $6.3 \mathrm{~mm}$. Recrystallization was studied by measuring the change in hardness (Rockwell-B) of cold-worked (CW) samples after a 1-hour heat treatment at temperatures from 300 to $550^{\circ} \mathrm{C}$. All samples for transmission electron microscopy (TEM) analysis, in addition to those examined optically to measure recrystallized grain size, were heated to $550^{\circ} \mathrm{C}$ in the tensile testing apparatus and held for 5 minutes before being quenched. This is the "start-of-test" condition.

Tensile testing was carried out in a 3-zone furnace at various temperatures from 450 to $550^{\circ} \mathrm{C}$ and constant true-strain rates from $10^{-5}$ to $10^{-2} \mathrm{~s}^{-1}$. The heating rate was approximately $20^{\circ} \mathrm{C} / \mathrm{min}$. An MTS servo-hydraulic tensile testing apparatus governed by an MTS 406 controller and a Wavetek model 75A waveform generator was utilized. The strain-rate sensitivity $(m=d \log \sigma / d \log \dot{\varepsilon})$ was measured as a 
Table I Alloy Compositions in Weight Percent (bal. Al)

\begin{tabular}{lcccccc} 
Alloy & $\mathrm{Mg}$ & $\mathrm{Mn}$ & $\mathrm{Zr}$ & $\mathrm{Cr}$ & $\mathrm{Fe}$ & $\mathrm{Si}$ \\
\hline 5083 & 4.93 & 0.81 & - & 0.19 & 0.08 & 0.03 \\
$5083(\mathrm{Zr})$ & 4.66 & 0.83 & 0.19 & 0.16 & 0.08 & 0.04 \\
$5083(\mathrm{Mn})$ & 4.80 & 1.60 & - & 0.18 & 0.08 & 0.03 \\
$5083(\mathrm{Zr}, \mathrm{Mn})$ & 4.70 & 1.60 & 0.2 & 0.18 & 0.09 & 0.05 \\
\hline
\end{tabular}

function of both strain and strain rate by bumping the strain rate to a higher value for short periods of strain (12). Most samples were strained to failure, but some were interrupted at strains of $0.2,0.7,1.0$ and 1.1 to assess cavitation and dynamic grain growth.

The microstructure was evaluated in a JSM 840 scanning electron microscope (SEM) and a JEOL $1200 \mathrm{FX}$ TEM operated at $120 \mathrm{keV}$. TEM discs were punched with the foil normal parallel to the sheet normal and electropolished in a mixture of $20 \% \mathrm{HClO}_{4}$ in methanol at $-20^{\circ} \mathrm{C}$. Precipitate analysis was carried out by energy dispersive $X$-ray spectrometry (EDS) in the SEM for large $(>5 \mu \mathrm{m})$ particles, and in the TEM for smaller $(<5 \mu \mathrm{m})$ particles. Particle size distributions were measured from SEM micrographs using computerized image analysis.

Grain boundaries were delineated by annealing at $180^{\circ} \mathrm{C}$ for 20 hours to precipitate $\mathrm{Mg}_{2} \mathrm{Si}$ at the boundaries, then etching in a $10 \%$ phosphoric acid solution at $50^{\circ} \mathrm{C}$. They were examined optically using normal light in both the "flat" (rolling surface) and long transverse directions. Grain sizes on the rolling surface were measured using the ASTM E112 standard intercept method with three concentric circles.

\section{Results}

A distribution of Mn-rich particles from 0.2 to $10 \mu \mathrm{m}$ was seen in each of the four alloys, but the $A$ and $B$ break-down rolling processes did not affect particles of different sizes equally. An example can be seen in Figure 1, which shows SEM micrographs of the base 5083 alloy for both $A$ and $B$ conditions. Image analysis revealed that particle densities for precipitates $>2 \mu \mathrm{m}$ in diameter were similar for the two cases, but there appeared to be substantially fewer precipitates smaller than 


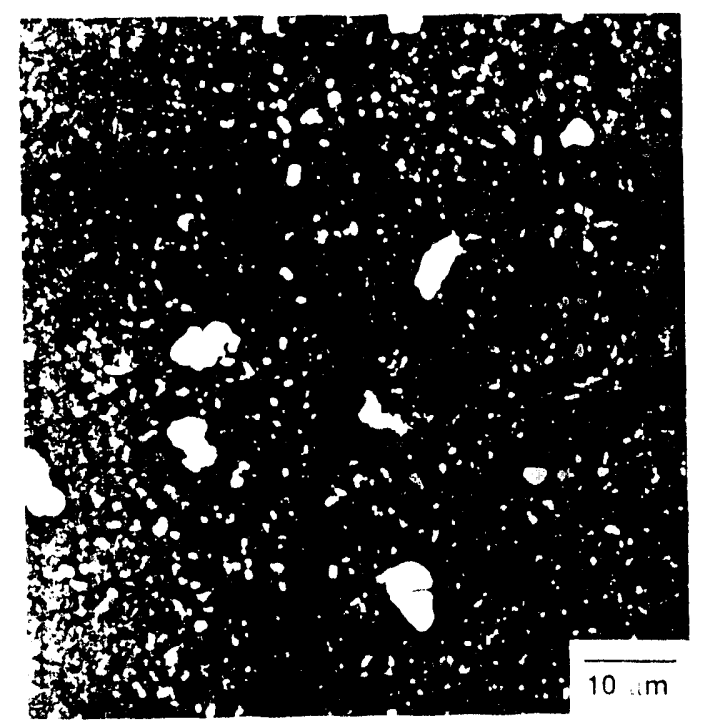

(a)

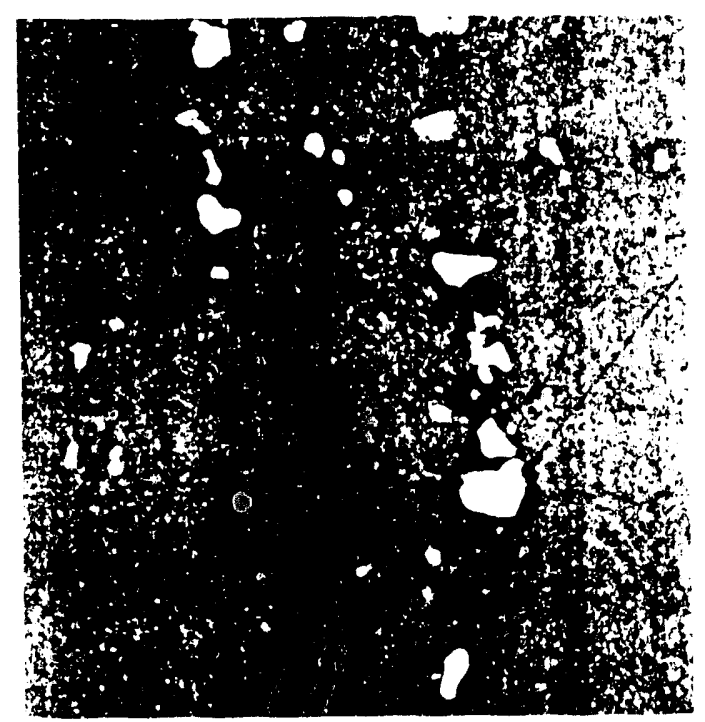

(b)

Figure 1- SEM micrographs of the base 5083 alloy rolled in the (a) $A$ condition and (b) B condition showing the apparent reduction in number density of small precipitates, but not for the larger dispersoids.

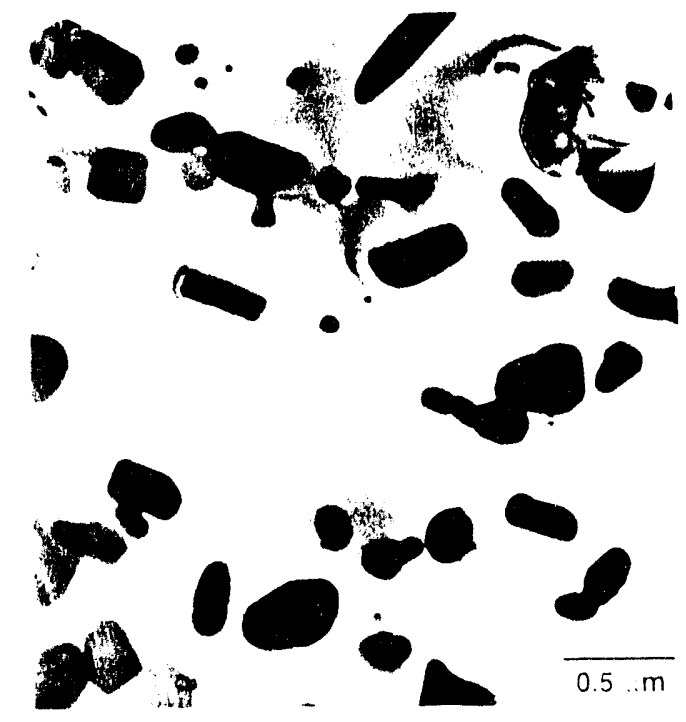

(a)

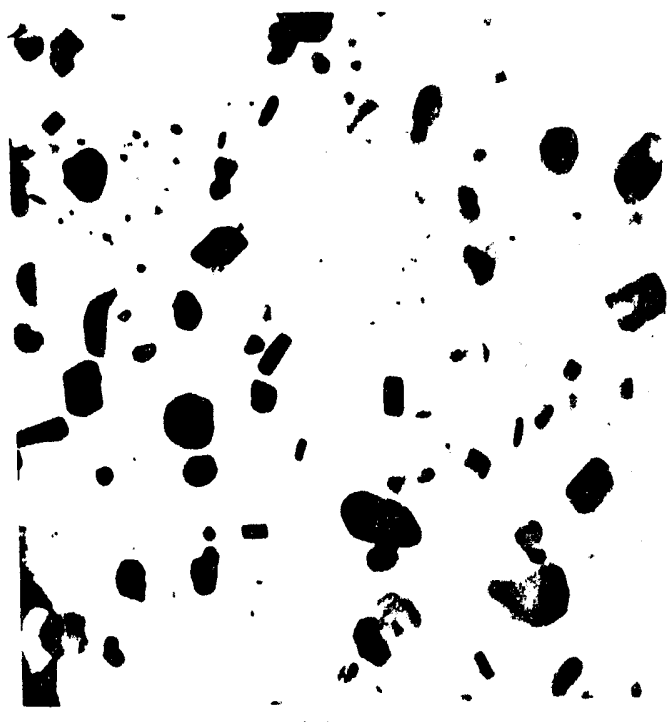

(b)

Figure 2- TEM micrographs of the base 5083 alloy rolled in the (a) $A$ condition and (b) $B$ condition. Note the decreased size and increased number density of the $\mathrm{Al}_{6}(\mathrm{Mn}, \mathrm{Cr})$ precipitates in the $\mathrm{B}$ condition.

$2 \mu \mathrm{m}$ in the B (lower temperature) condition. The reason for this reduction is seen in the TEM micrographs of Figure 2 , which show that the sizes of the smaller precipitates were decreased in the $B$ condition and therefore more difficult to resolve in the SEM. Analysis of the small precipitates using EDS confirmed that they were $\mathrm{Al}_{6}(\mathrm{Mn}, \mathrm{Cr})$. Though the base alloy is used in this comparison, the trends were the same for each of the alloys studied. 
The precipitate structure of the base alloy was further modified with the addition of $\mathrm{Zr}$ and/or $\mathrm{Mn}$. EDS and electron diffraction analysis indicated that $\mathrm{Zr}$ is primarily present as incoherent precipitates ranging in size from 50 to $100 \mathrm{~nm}$ in diameter. An example is shown in Figure 3, which shows the small $\mathrm{Zr}$-rich precipitates distributed in an inhomogeneous fashion among the larger $\mathrm{Al}_{6} \mathrm{Mn}$ particles. The distribution of $\mathrm{Zr}$-rich particles was similar in the $\mathrm{Zr}+\mathrm{Mn}$ alloy. In contrast, the addition of $M n$ to both the base alloy and the $\mathrm{Zr}$ alloy resulted in only a small increase in submicron precipitates, but the density of precipitates larger than $2 \mu \mathrm{m}$ increased four fold. This is demonstrated by the SEM micrographs of Figure 4.

Differences in the precipitate structures of these alloys resulted in a significant effect on the recrystallization/recovery behavior. In the $A$ condition, all four alloys were completely recrystallized by $300^{\circ} \mathrm{C}$ as indicated by a drop in $R_{B}$ hardness from the low $80 \mathrm{~s}$ to the high $30 \mathrm{~s}$. However, the full hardness decrease in both the $\mathrm{Zr}$ and $\mathrm{Zr}+\mathrm{Mn}$ alloys was suppressed until temperatures of 400 and $450^{\circ} \mathrm{C}$, respectively, when they were in the $\mathrm{B}$ condition.

The data from "start-of-test" grain-size measurements also point to precipitate effects in the alloys (see Table II). Compared to the base alloy with a grain size of $6.7 \mu \mathrm{m}$, the $\mathrm{Zr}$ addition increased, and the $\mathrm{Mn}$ addition decreased, the grain size by $10 \%$. The combination of both additions decreased the grain size by nearly $30 \%$. For the alloys in the $B$ condition the grains were approximately twice as large as their A condition counterparts, but the trends with alloy addition were the same. Interestingly, when examining the samples in the long

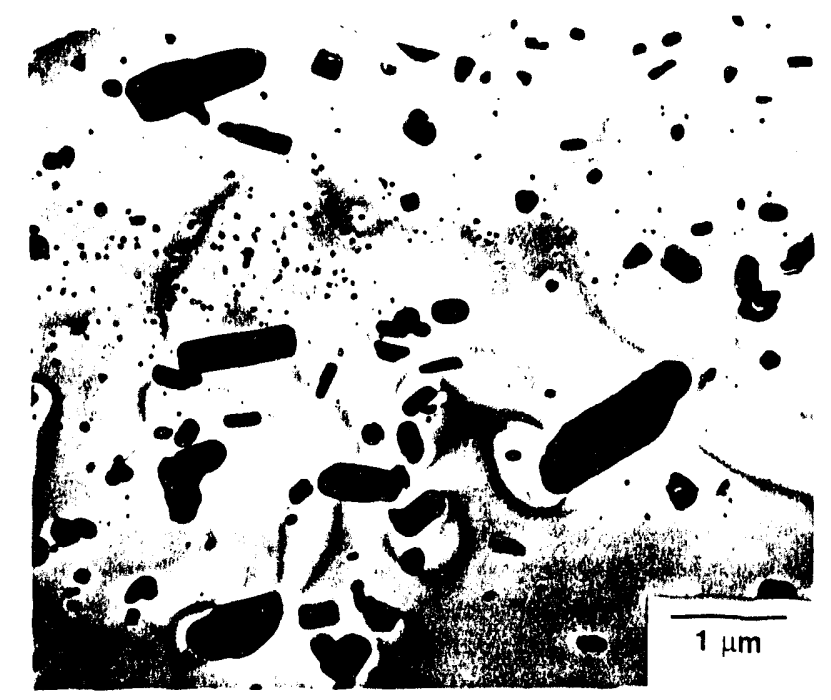

Figure 3- A TEM micrograph of the Zr-alloy (in the A condition) revealing the submicron $\mathrm{Zr}$-rich particles that are intermixed with the larger Mn-rich precipitates. 


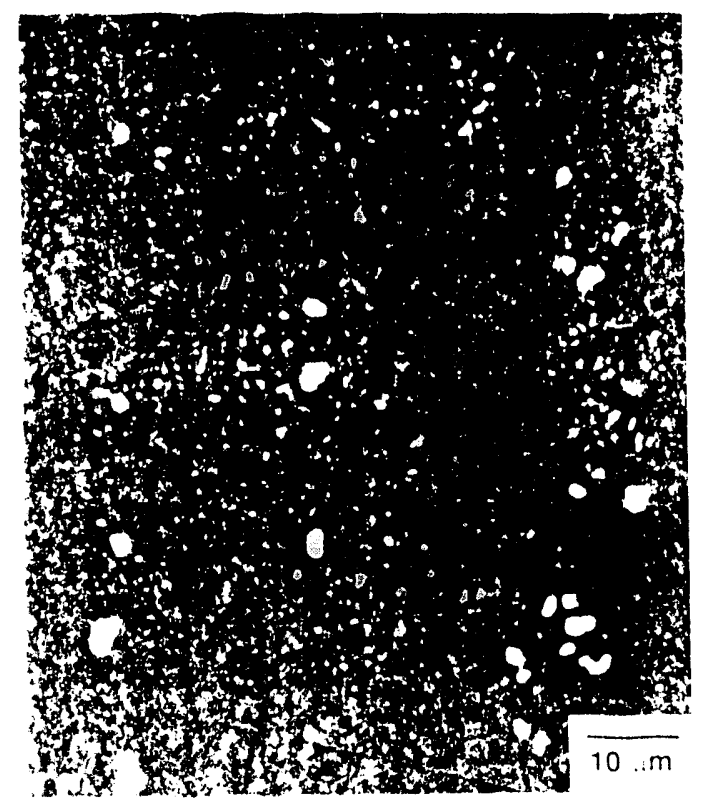

(a)

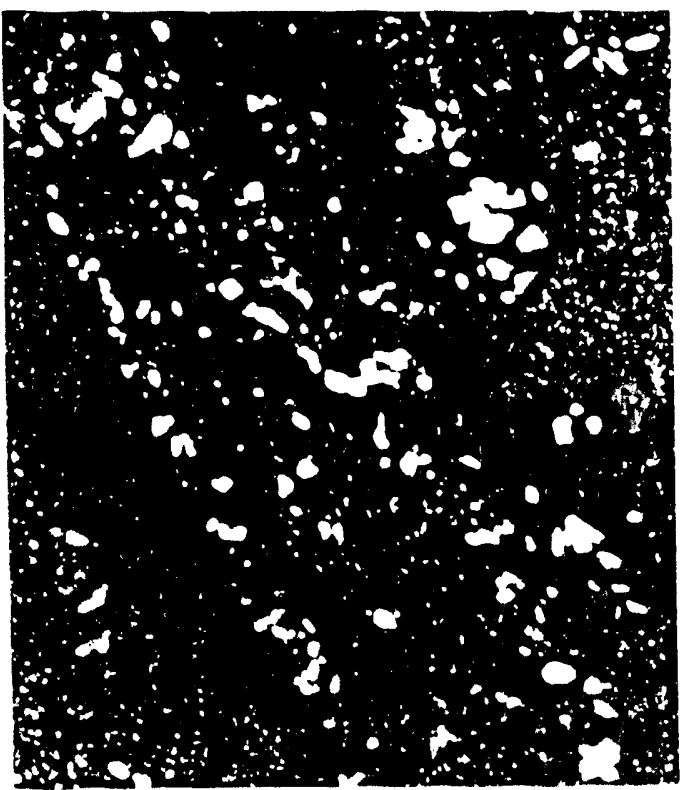

(b)

Figure 4- A comparison of the precipitate structure of (a) the base 5083 alloy and (b) $5083+\mathrm{Mn}$ as seen in the SEM. The density of dispersoids $>2 \mu \mathrm{m}$ was increased four times by the $\mathrm{Mn}$ addition.

Table $\|$ Grain Size After $5: 1 \mathrm{Cold}$-Roll and Heat-Up to $550^{\circ} \mathrm{C}$

\begin{tabular}{lrr}
\hline \multirow{2}{*}{ Alloy } & Heat Treatment & Grain Size $(\mu \mathrm{m})$ \\
\hline 5083 & A & 6.7 \\
$5083(\mathrm{Zr})$ & B & 13.4 \\
& A & 7.5 \\
$5083(\mathrm{Mn})$ & B & 15.3 \\
$5083(\mathrm{Zr}, \mathrm{Mn})$ & A & 5.9 \\
& B & 9.4 \\
& A & 4.8 \\
& B & 9.5 \\
\hline
\end{tabular}

transverse direction, the grains were equiaxed in the $A$ condition, but severely elongated in the $B$ condition for all alloys. Examination of these materials in the TEM indicated that there are few if any dislocations present in the "start-of-test" condition, and that the majority of grain boundaries are high-angle.

Figure 5 shows the strain-rate sensitivity of the four alloys in the $A$ condition as a function of strain (for a strain range of 0.5 to 1.1) at 


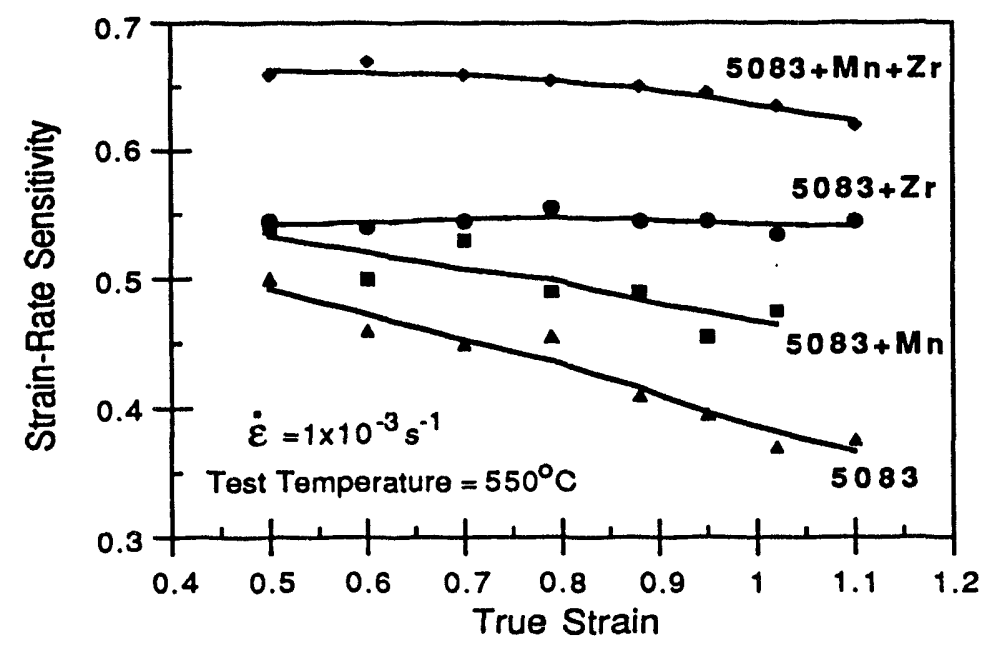

Figure 5- Strain-rate sensitivity as a function of strain for the four alloys in the A condition. Note that the range of strain is 0.5 to 1.1 in this graph.

$550^{\circ} \mathrm{C}$ and a strain rate of $1 \times 10^{-3} \mathrm{~s}^{-1}$. All of the alloys had an m-value of at least 0.5, which is one of the criteria for superplasticity (13). At a strain of 0.5 , the addition of $\mathrm{Zr}$ or $\mathrm{Mn}$ increased the m-value from 0.5 for the base alloy to $\sim 0.55$. The $\mathrm{Zr}+\mathrm{Mn}$ alloy showed a further increase to 0.66 . However, whereas the strain-rate sensitivity of AA5083 and $5083+\mathrm{Mn}$ steadily decreases with strain, the $\mathrm{Zr}$ and $\mathrm{Zr}+\mathrm{Mn}$ alloys show an almost constant $m$-value over this strain range. The large, nonequiaxed grains present in the $B$ condition caused a lower strain-rate sensitivity for all alloys, but the trends with alloy additions remained comparable to the A condition.

To observe differences in hot deformation characteristics, tests were interrupted at several strains and the degree of cavitation was measured. Qualitative results can be seen in Figure 6, which shows cavitation in three of the alloys after deformation at $1 \times 10^{-3} \mathrm{~s}^{-1}$ and $550^{\circ} \mathrm{C}$ to a strain of 1.1 . Alloys with $\mathrm{Zr}$ or $\mathrm{Zr}+\mathrm{Mn}$ show much less cavitation than the base alloy at this strain. In fact, the $\mathrm{Zr}+\mathrm{Mn}$ alloy is hardly cavitated at all. The low cavitation in the Zr-containing alloys is consistent with their high $(>0.5) \mathrm{m}$-values at this strain.

\section{Discussion}

The results of grain-size measurements and hot deformation response of these four alloys indicate that a broad precipitate size distribution results in the finest grains and greatest improvement in superplastic 


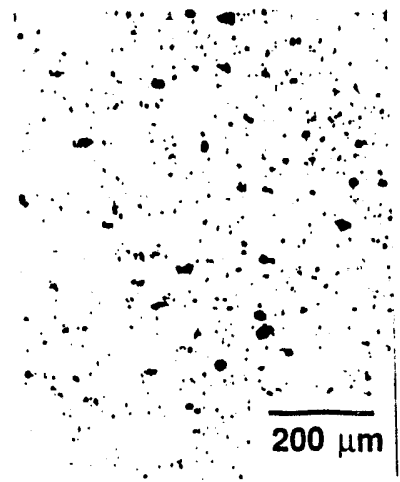

(a)

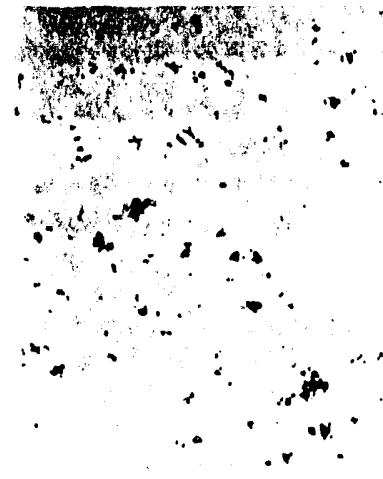

(b) (c)

Figure 6- Optical micrographs of the gage center in (a) 5083, (b) the $\mathrm{Zr}$ alloy and (c) the $\mathrm{Zr}+\mathrm{Mn}$ alloy at a strain of $1.1 \quad\left(\dot{s}=1 \times 10^{-3} \mathrm{~s}^{-1}\right.$, $\mathrm{T}=550^{\circ} \mathrm{C}$ ). Tensile axis is horizontal.

behavior. This distribution consists of large $(>1 \mu \mathrm{m})$, mid-sized $(0.5$ to $1 \mu \mathrm{m})$ and small $(<0.5 \mu \mathrm{m})$ intermetallic particles. It is the combination of particles with these sizes that results in the optimum hot deformation characteristics.

There are two sources for intermetallic particles in these alloys: primary dispersoids that form during casting and precipitates that come out of solution during subsequent TMP. From the grain-size results for the base 5083 and Mn alloy there appears to be an increase in recrystallization nuclei and/or increase in grain-boundary pinning when the number of dispersoids is higher. However, in the $B$ condition, where the precipitates are smaller and more dense, the grains are larger and non-equiaxed when compared to the A condition, even in the higher Mn-content alloy. This type of behavior was also seen by Gardner and Grimes (10) in an Al-0.5Zr material that had a fine dispersion of precipitates and large, non-equiaxed "recrystallized" grains. It appears that the substructure is bound by the small precipitates and there is no recrystallization, just extensive recovery.

The addition of $\mathrm{Zr}$ to the base alloy resulted in a larger grain size, but also increased the $m$-value and improved cavitation resistance. It is not clear why the presence of small precipitates resulted in an increased grain size. The increase in strain-rate sensitivity probably comes about by the hardening of the matrix to dislocation motion by the $\mathrm{Zr}$-rich precipitates, resulting in increased grain boundary sliding (13).

The $\mathrm{Mn}$ addition reduced the grain size and increased strain-rate sensitivity, but it was the combination of $\mathrm{Mn}$ and $\mathrm{Zr}$ additions that gave the smallest grain size and best superplastic response. The trend in grain size with alloy addition is an indication that the $\mathrm{Zr}$ and $\mathrm{Mn}$ 
additions are working synergistically. Addition of $Z r$ to the base alloy increased the grain size, but when $\mathrm{Zr}$ was added to the $\mathrm{Mn}$ alloy, the grain size decreased.

The smallest precipitates appear to be effective at pinning dislocations but not high-angle grain boundaries. This includes the $\mathrm{Zr}$ rich precipitates and the small $\mathrm{Al}_{6}(\mathrm{Mn}, \mathrm{Cr})$ precipitates in the $B$ condition. Particles in the 0.5 to $1.0-\mu \mathrm{m}$ range can pin grain boundaries (as seen in TEM micrographs), but are probably not good nuclei for new grains during recrystallization. The larger dispersoids, however, make good nuclei. The combination of particle sizes in the alloy with both $\mathrm{Zr}$ and $\mathrm{Mn}$ additions results in a smaller recrystallized grain size and restricts high-temperature grain growth, which leads to better superplastic deformation.

\section{Conclusions}

1) A downward shift in $\mathrm{Al}_{6} \mathrm{Mn}$ precipitate size distribution was produced by performing the break-down rolling in AA5083-based alloys at lower temperatures than standard. The $\mathrm{Zr}$ and $\mathrm{Zr}+\mathrm{Mn}$ alloys then retain their $\mathrm{CW}$ hardness to a higher temperature.

2) Doubling the $\mathrm{Mn}$ content of the base alloy resulted in a four-fold increase in dispersoid density, a reduced recrystallized grain size and a slightly higher m-value during hot tensile deformation.

3) A distribution of fine $(<100 \mathrm{~nm})$ precipitates was created by adding $0.2 \% \mathrm{Zr}$ to the base alloy. This resulted in a slightly increased grain size, but also an increased strain-rate sensitivity that was stable with strain, and reduced cavitation. The $\mathrm{Zr}$ precipitates are incoherent, and non-uniformly distributed in the matrix.

4) When both $\mathrm{Zr}$ and $\mathrm{Mn}$ are added to $\mathrm{AA5083}$ they act synergistically to yield the smallest grain size, highest strain-rate sensitivity and lowest cavitation levels of the alloys tested. This is due to the wide size distribution of particles in this alloy.

\section{Acknowledgments}

The assistance of D. Criswell in performing the mechanical tests is gratefully acknowledged. We also thank Professor C.H. Hamilton for his help and advice. This work was supported by the Materials Sciences Division, Office of Basic Energy Sciences, U.S. Department of Energy (DOE), under Contract DE-AC06-76RLO 1830. 


\section{References}

1. D.J. Lloyd, "The deformation of commercial aluminum-magnesium alloys," Metall. Trans. A, 11 (1980), 1287-1294.

2. H. Iwasaki et al., "Superplastic deformation characteristics of $\mathbf{5 0 8 3}$ aluminum alloy," Superplasticity in Advanced Materials, ed. S. Hori, M. Tokizane and N. Furushiro (Osaka, Japan: The Japan Society for Research on Superplasticity, 1991), 447-452.

3. H. Imamura and N. Ridley, "Superplastic and recrystallisation behaviour of a commercial Al-Mg alloy 5083," ibid, 453-458.

4. H. Watanabe, K. Ohori and Y. Takeuchi, "Superplastic behavior of AlMg-Cu alloys," Transactions ISIJ, 27 (1987), 730-733.

5. J.S. Vetrano et al., "Superplastic behavior in a commercial 5083 aluminum alloy," to be published in Scripta Metall., March 1, (1994).

6. T. Sheppard and M.G. Tutcher, "Development of duplex deformation substructure during extrusion of a commercial Al- $5 \mathrm{Mg}-0.8 \mathrm{Mn}$ alloy," Met. Sci., 14 (1980), 579-589.

7. H.J. McQueen et al., "Hot deformation and dynamic recrystallization of Al-5Mg-0.8Mn alloy," Met. Sci., 18 (1984), 395-402.

8. E. Evangelista, H.J. McQueen and E. Bonetti, "Interaction between $(\mathrm{MnFe}) \mathrm{Al} \mathrm{I}_{6}$ particles and substructure formed during hot working of Al$5 \mathrm{Mg}-0.8 \mathrm{Mn}$ alloy," Deformation of Multi-Phase and Particle Containing Materials, ed. J.B. Bilde-Sørensen, N. Hansen, A. Horsewell, T. Leffers and H. Lilholt (Roskilde, Denmark: Risø National Laboratory, 1984), 243250.

9. B.M. Watts et al., "Superplasticity in Al-Cu-Zr alloys Part II: Microstructural study," Met. Sci., 10 (1976), 198-206.

10. K.J. Gardner and R. Grimes, "Recrystallization during hot deformation of aluminum alloys," Met. Sci., 13 (1979), 216-222.

11. E. Nes, "Hot deformation behaviour of particle-stabilized structures in Zr-bearing Al alloys," ibid, 211-215.

12. T.G. Langdon and P. Yavari, "A recommended procedure for determining the strain rate sensitivity in superplasticity," Scripta Metall, 17 (1983), 435-440. 
13. O.D. Sherby and J. Wadsworth, "Superplasticity-Recent advances and future directions," Progress in Mat. Science, 33 (1989), 169-221. 

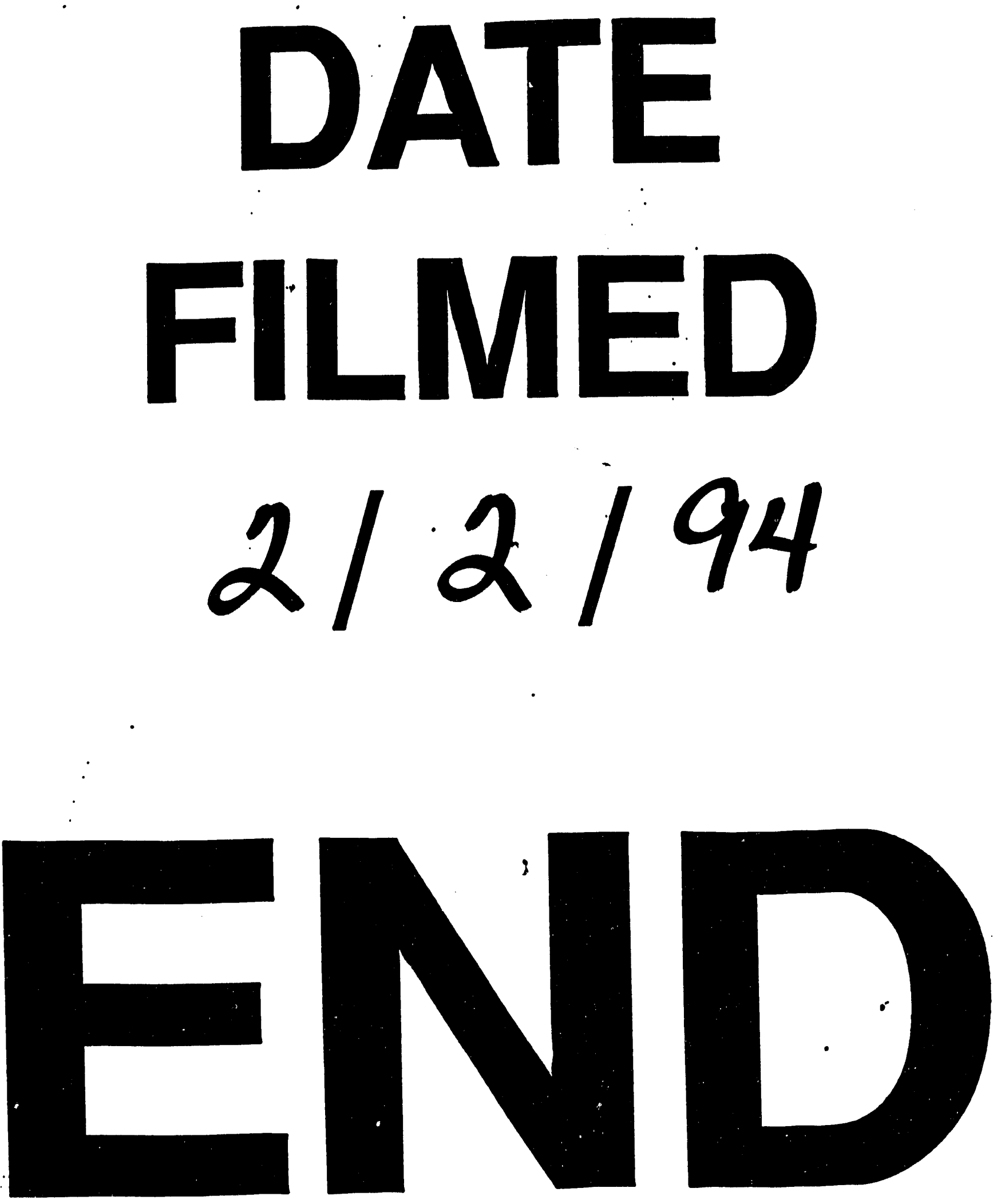


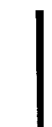

